\title{
Possibilidades de Atuação do Psicólogo no Programa Saúde da Família: A Experiência de Bonito-Ms
}

Psychologist interations possibilities in the family health programm: The experience of Bonito-ms.
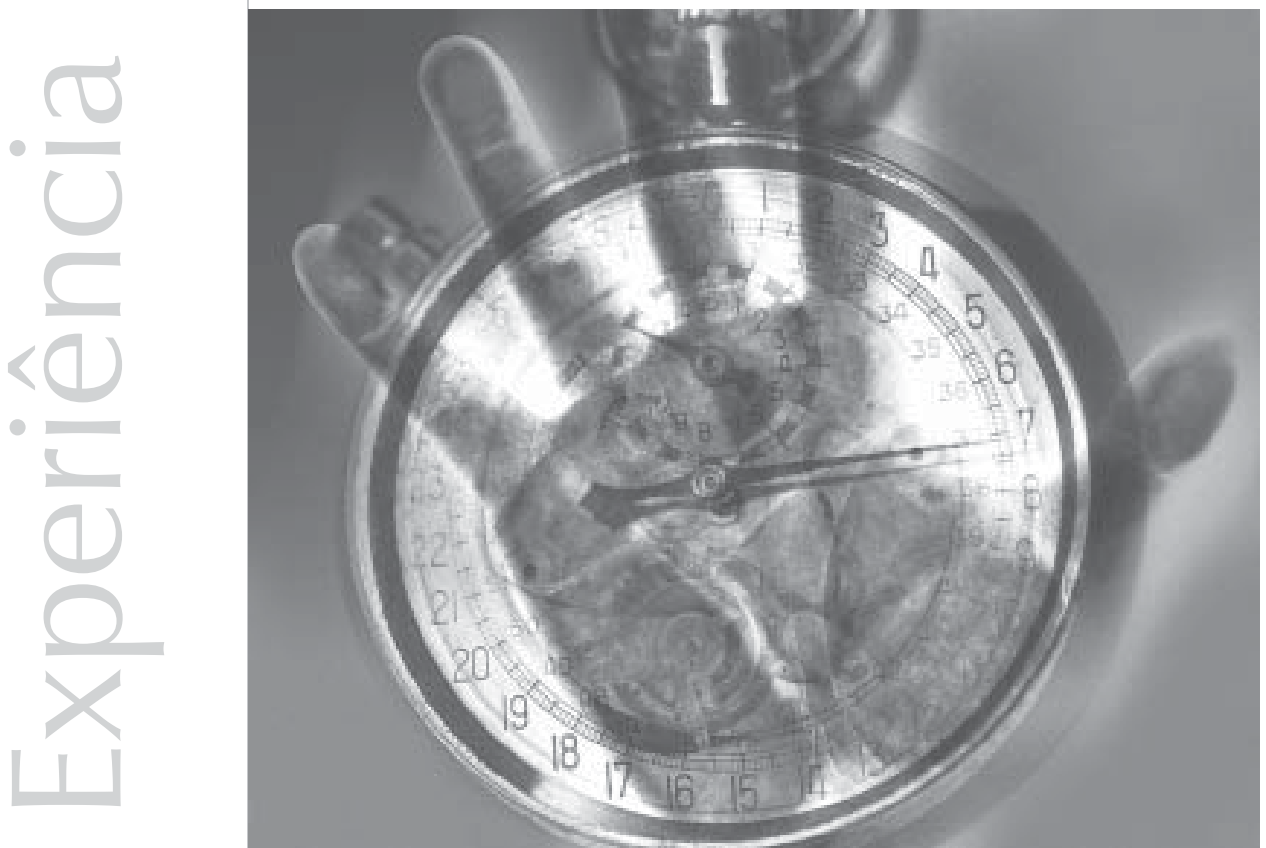
Resumo: O trabalho resulta de estudo realizado junto aos participantes do Programa de Saúde da Família - PSF, no município de Bonito, no Estado de Mato Grosso do Sul, no ano de 2003. O estudo objetivou identificar as possibilidades de atuação do psicólogo nas equipes de PSF, por meio da opinião dos profissionais e usuários. Trata-se de um estudo descritivo com abordagem qualitativa, utilizando-se de questionários para a coleta dos dados. Os resultados apontaram que a atuação do psicólogo junto à equipe, orientando ou atendendo a demanda por saúde mental, proporciona atendimento integral e resolutividade nos serviços ofertados, por meio de ações interdisciplinares. Destaca-se a promoção da integração entre os membros da equipe e, desta com a comunidade. Tem uma importante contribuição na promoção da saúde, desenvolvendo ações educativas/preventivas; além disso, favorece a humanização do atendimento, por ser um profissional que ouve e orienta os profissionais, os indivíduos e, as famílias.

Palavras-chave: atenção básica; Programa de Saúde da Família; interdisciplinaridade; psicologia.

Abstract: This paper is the result of a study conducted among the family health's program participants, in the city of Bonito, Mato Grosso do Sul state, in the year 2003. The aim of the study was to identity the psychologist intervention possibilities in the PSF program through the opinions of the professionals and the program users. It is a descriptive study with a qualitative approach, using a questionnaire as an instrument to collect data. The results point out that the intervention of the psychologist in mental health helps to provide full attention at the offered health services beyond multidisciplinary actions. We also point out the integration among the health team members, and with the community. It has a great contribution to health promotion because allows developing educative/preventive actions and, besides, contributes to humanize the attention to the patient and their families.

Key-words: basic attention; Program of Health of the Family; interdisciplinary action;, psychology.

Com a implantação em 1994 pelo Ministério da Saúde, do Programa de Saúde da Família-PSF, como uma estratégia para a reorganização do sistema de saúde a partir da reestruturação da atenção básica em saúde, o programa passou a receber incentivos governamentais dos níveis federal e estadual, para a sua implantação nos municípios brasileiros.

Por ocasião da criação do Programa, o Ministério da Saúde preconizou que uma equipe de PSF deveria ser multiprofissional composta, no mínimo, por um médico (preferencialmente generalista), um enfermeiro, um auxiliar de enfermagem e quatro a seis agentes comunitários de saúde-ACS. A essa equipe foi dada a incumbência de desenvolver um novo processo de trabalho, consubstanciado no conhecimento da realidade dos indivíduos inseridos no contexto de suas famílias e no ambiente comunitário, tendo que, com a participação da comunidade, elaborar um plano local para o enfrentamento do processo saúde-doença.
Essa reorientação do modelo assistencial requereu profundas mudanças na prática assistencial dos profissionais envolvidos, os quais tiveram que assumir novos papéis sociais e buscar novos conhecimentos, com o propósito de buscar soluções para os problemas de saúde em nível individual e coletivo.

O enfoque de vigilância a saúde dada pela estratégia do PSF, a recomendação para o mais efetivo aproveitamento dos recursos disponíveis, adequando-o às necessidades da população, e ainda a determinação em cumprir os princípios básicos que norteiam a construção do Sistema Único de Saúde - SUS, da universalização, da integralidade, da equidade, da descentralização e da participação popular, pode, por vezes, significar dificuldades cotidianas para profissionais que possam estar mais habituados a uma visão elitista, tradicional e segmentada do processo saúde-doença, culminando em situações de grande"estresse"emocional para muitos dos profissionais, componentes de equipes. 
Em pesquisa realizada pela Fundação Oswaldo Cruz e pelo Ministério da Saúde, em agosto de 2000, com vistas ao levantamento do perfil dos médicos e enfermeiros do Programa de Saúde da Família no Brasil, constatou-se que 68,38\% dos médicos e 59,60\% dos enfermeiros consideraram seu trabalho desgastante, apontando como causas o vínculo empregatício precário, a dificuldade de acesso às áreas de trabalho, o excesso de expediente, falta de recursos (humanos, materiais e até de medicamentos), baixa remuneração e deficiências dos sistema de referência e contra referência. Destaca-se que os dados coletados entre janeiro e junho de 1999, apontam ainda que a região centro-oeste contava, na época, com a menor quantidade de equipes do país: apenas 4,34\% do total de equipes do Brasil (Machado, 2000).

Os dados acima, tornam-se relevantes para demonstrar o quão nova é a experiência com o Programa de Saúde da Família na região CentroOeste e que, de fato, pode tornar-se desgastante em maior ou menor grau para os profissionais, principalmente em se tratando de uma estratégia revolucionária e nova que inclusive desloca o poder do profissional médico, dividindo-o com outros profissionais e com a própria comunidade. Essa característica de atuação inter e multiprofissional, de responsabilidade integral e compartilhada sobre a população em sua área de abrangência, permitiu a incorporação de outros profissionais, de acordo com as demandas apresentadas.

Por isso, passados alguns anos de sua criação o próprio Ministério da Saúde previu a ampliação da equipe mínima, incorporando a equipe de saúde bucal (cirurgião-dentista, técnico de higiene dental e/ou auxiliar de consultório dentário), inclusive, aumentando os incentivos financeiros aos municípios que implantassem equipe ampliada. Além disso, os municípios perceberam que as ações de promoção e proteção da saúde, recuperação do dano e reabilitação de seqüelas, são favorecidas quando atendidas no nível da atenção primária e, assim, já não é de todo incomum encontrarmos assistentes sociais, nutricionistas, psicólogos ou outros profissionais, compondo equipes de PSF.

O município de Bonito no Mato Grosso do Sul ao implantar o Programa de Saúde da Família, estratégicamente o fez com a participação de um profissional psicólogo, cuja atuação permeou todo o processo de implantação, desde o cadastramento e a sensibilização das famílias, o apoio psicológico aos profissionais frente ao novo ambiente e processo de trabalho e a realização do diagnóstico comunitário, permanecendo na equipe por um período de tempo, atendendo a demanda por saúde mental e apoiando os programas de saúde implantados na Unidade Básica de Saúde da Família-UBSF.

Passados quase três anos, atendendo a reorganização dos serviços pela nova gestão local, o profissional psicólogo deixou de ser cadastrado na equipe de PSF, sendo remanejado para a Unidade Central de Referência, passando a atuar como profissional de apoio, e atuando na equipe de PSF, apenas por dois dias da semana. Além disso, no ano de 2001, ao implantar uma nova equipe, aumentando a cobertura populacional pelo PSF no município, esta não contou com a participação do profissional psicólogo em sua composição.

Por isso, este estudo teve por finalidade identificar as possibilidades de atuação do profissional psicólogo em uma equipe de PSF, apresentadas pelos principais atores envolvidos nesse processo: os componentes da equipe e os usuários dos serviços.

\section{A saúde mental na saúde da família}

A Lei No. 10.216, de 06 de abril de 2001 (Brasil), dispõe sobre a proteção e os direitos das pessoas portadoras de transtornos psíquicos e redireciona o modelo assistencial em saúde mental, determina, no seu item IX, do parágrafo único, do Artigo 2., 
que"é direito da pessoa portadora de transtorno psíquico ser tratada, preferencialmente, em serviços comunitários de saúde mental."Aponta portanto, para a inclusão da atenção em saúde mental na atenção básica, como possível forma de manter o portador de transtorno próximo a comunidade, família e meio social e facilitar ações de educação e prevenção.

A proposta preliminar do Plano de Inclusão das Ações de Saúde Mental na Atenção Básica, do Ministério da Saúde, define como estratégia privilegiada das ações de Saúde Mental, a sua inclusão na atenção básica e, nesta, o trabalho com o Programa de Saúde da Família, destacando que:

O PSF consiste em um novo modelo de atenção centrado na lógica da vigilância à saúde e qualidade de vida, dirigido à família e à comunidade, e inclui desde a proteção e a promoção à saúde até o diagnóstico e o tratamento das doenças. O perfil específico dos profissionais desses programas, envolvidos com o bem-estar das comunidades, é o da construção de compromisso, disponibilidade, intimidade e de relações de confiança com as mesmas. Nesse mesmo período, o campo de atenção à saúde mental passa por importantes transformações conceituais e operacionais, reorientando-se o modelo historicamente centrado na referência hospitalar por um novo modelo de atenção descentralizado e de base comunitária.

A incorporação de ações de saúde mental na atenção básica à essa rede diversificada de serviços (PSF/PACS), contribuirá para alavancar este novo modelo, oferecendo melhor cobertura assistencial dos agravos mentais e maior potencial de reabilitação psicossocial para os usuários do SUS (Ministério da Saúde, 2001 b).

Conforme relata Cardoso (2002), o PSF em Vespasiano, Minas Gerais, incluiu um estagiário de psicologia, supervisionado pelo Departamento de Psicologia da Universidade Federal de Minas Gerais, em cada uma de suas nove equipes. A inserção do profissional de psicologia no PSF objetiva:

Atuar junto a comunidade, difundindo informações sobre saúde mental e fazendo uma identificação das pessoas portadoras de diabetes e hipertensão arterial com comprometimentos emocionais que demandem assistência psicológica; possibilitar um espaço terapêutico para que as pessoas possam trocar experiências e desenvolver suas potencialidades, a fim de usá-las de forma mais adequada no atendimento de suas necessidades, esperando-se, com isso, beneficiar não apenas o seu quadro clínico, mas também despertá-las para seu potencial na construção de uma vida com mais qualidade; atuar junto a equipe do PSF, colaborando com outros profissionais de saúde, visando a integrar esforços, estimular a reflexão e a troca de informações sobre a população atendida, de modo a facilitar sua avaliação e evolução clínica; proporcionar ao estudante de psicologia a aplicação dos conceitos obtidos no curso numa atuação tanto terapêutica quanto preventiva, mediante $\mathrm{o}$ atendimento supervisionado dos pacientes e do trabalho desenvolvido junto à equipe interdisciplinar (Cardoso, 2002, p. 4).

De acordo com a mesma autora, a atuação ocorre através de grupos informativos, grupos psicoterápicos, dinâmicas de grupo, teatro informativo, visita domiciliar e atendimento individual, além do trabalho com características interdisciplinares desenvolvido com a equipe, buscando discutir casos, textos específicos e desmistificar a psicologia. Por fim, a experiência é considerada positiva"(...) os avanços obtidos junto à clientela e à equipe apontam para a importância da inclusão efetiva de um psicólogo na equipe do PSF "(Cardoso, 2002, p.8).

Pereira et. al. (2003) relatam que em Sobral, no estado do Ceará, a rede de saúde mental é composta também, pelas equipes do Programa de Saúde da Família existentes, de forma a integrar, incorporar, as ações de saúde mental na atenção básica a saúde. A experiência, considerada 
positiva, iniciou-se a partir da implantação do Curso de Residência em Saúde da Família de Sobral - RSFS, quando, a partir da detecção da necessidade, o profissional de saúde mental passa a supervisionar e capacitar as equipes do PSF através da discussão de casos clínicos, atendimento compartilhado (avaliação de casos clínicos com técnicos, usuários e familiares), visitas domiciliares, capacitação quanto ao diagnóstico e manejo de psicofármacos. Após a primeira experiência a capacitação passa a ocorrer de forma mais sistematizada, objetivando:

auxiliar as equipes de PSF na transformação do modelo de atenção à saúde, habilitar o profissional de saúde a exercitar uma escuta qualificada que o auxilie a lidar com aspectos psicossociais de seus pacientes (...); b) capacitar as equipes do PSF na resolução das demandas mais prevalentes em saúde mental. Em termos gerais a abordagem resolutiva de transtornos mentais menores manifestos sob a forma de queixas somáticas e 'nervosas', além de quadros reativos relacionados a problemas sócio-familiares e abuso de psicotrópicos; c) apoiar e supervisionar as equipes de PSF no desenvolvimento de técnicas de intervenção coletiva e promoção da saúde como: grupos com pacientes somáticos e usuários abusivos de psicofármacos, utilização de recursos da comunidade, atendimento familiar, etc.; d) orientar as equipes de PSF na implementação de estratégias de reintegração social de pacientes psicóticos: acompanhamento de pacientes egressos, acompanhamento domiciliar e procedimentos de reabilitação psicossocial e desenvolvimento de estratégias de redução da estigmatização da loucura na comunidade (Pereira et. al. 2003).

No município de Cabedelo, no Estado de Pernambuco, Ferreira Filha et. al. (2003) relatam que a partir de um levantamento de problemas, realizado pela Universidade Federal de Pernambuco constatou-se que as ESF não estavam sensibilizadas para a promoção de saúde em geral, incluindo a saúde mental; foi proposto um processo programado de sensibilização através de oficinas, objetivando a preparação das ESF para a implementação de novas estratégias de atendimento em saúde mental inserida na atenção básica e, o desenvolvimento global da equipe, uma vez que se constatou que:

Tais equipes necessitam preparar-se para enfrentar novos desafios, desenvolvendo o potencial criativo, exercitando não só o conhecimento técnico para abordar problemas de saúde/doença, mas sobretudo valorizando a sua prática como sujeito e ator social, aprendendo a construir vínculos solidários mais fortes tanto no trabalho quanto na própria família, apoiado-se nas redes solidárias e percebendo que nesse contexto ele é um coadjuvante na construção de um processo político social mais enriquecedor, onde a saúde é o seu campo de atuação com interface com outros campo: cultura, educação, economia, trabalho, lazer e religiosidade (Pereira Filha et. al., 2003).

De acordo com Pinto (2002), em um trabalho desenvolvido no município de Quissamã, no estado do Rio de Janeiro, foi possível capacitar toda uma rede de profissionais de saúde inseridos na atenção básica, inclusive, para um trabalho conjunto com a equipe de saúde mental, especialmente na atenção ao chamado 'paciente grave' e, em relação aos resultados obtidos destaca como o mais relevante a descoberta de que:

O Agente Comunitário de Saúde revelou-se como o profissional que melhor e mais rapidamente responde à capacitação, passando a representar, na comunidade, o papel de referência para as situações de crise. Considerando que são moradores das comunidades, percebemos o potencial de transformação da cultura de exclusão que têm cada um desses profissionais. A discussão a respeito da Saúde Mental ganhou uma circulação até então inédita na região (Pinto, 2002).

\section{Metodologia}

Foi realizado um estudo descritivo com abordagem qualitativa, utilizando-se questionários para a coleta de dados primários. 
O estudo foi realizado no município de Bonito no Estado de Mato Grosso do Sul.

Pretendia-se entrevistar a totalidade de 18 componentes das duas equipes de PSF existentes no município. No entanto, um profissional médico não aderiu à pesquisa, e assim, o número de participantes das equipes de PSF resultou em 17 profissionais, sendo: 01 médico, 02 enfermeiros, 01 cirurgião dentista, 03 auxiliares de enfermagem, 01 auxiliar de consultório dentário, 01 técnico de enfermagem e 08 agentes comunitários de saúde. Com o objetivo de dar paridade entre os componentes das equipes, determinou-se uma amostra de 18 usuários, sendo dez da área do PSF Rincão Bonito e oito do PSF Vila Donária (amostra por conveniência).

Os profissionais componentes das equipes foram abordados pelos gerentes das UBSF em dia e horário previamente agendados.

Para a coleta dos dados referentes aos representantes da população, os 18 usuários foram escolhidos da seguinte forma: foram abordadas as primeiras dez pessoas que se apresentaram para consulta médica no PSF Rincão Bonito e as primeiras oito pessoas que se apresentaram para consulta médica no PSF Vila Donária, na segunda segunda- feira do mês de agosto de 2003.

As questões que nortearam as entrevistas foram: A) para os componentes das equipes de PSF: 1) Cargo/função na equipe? 2) Há quanto tempo trabalha na equipe? 3) Tem conhecimento da real situação da população com relação a saúde mental? 4) Como está sendo feito o atendimento à saúde mental da população adscrita à sua equipe? 5) Em que atividade desenvolvida pela equipe você pensa que o psicólogo seria importante? 6) Se na equipe houvesse um psicólogo, que contribuições poderia trazer: a) para a equipe; b) para a população; B) Para os Usuários: 1) Sexo; 2) Idade) 3) Ocupação) 4) Você sabe o que é ou o que faz um psicólogo? 5) Você ou alguém de sua família já precisou ser atendido por um profissional psicólogo? 6) Você acha que na equipe de saúde da família deveria ter um psicólogo? Por que?

Para a coleta dos dados foram consideradas as orientações contidas na Resolução 196/96, do Conselho Nacional de Saúde, tendo os participantes assinado o Termo de Consentimento Livre e Esclarecido-TCLE. Antecedendo a assinatura foi feita a apresentação do pesquisador e da pesquisa, seus objetivos e a razão da escolha do entrevistado. Foi-lhes assegurado a garantia do anonimato e informado sobre a inexistência de possibilidade de sua identificação a partir dos resultados da pesquisa.

\section{Resultados e discussão}

Os resultados da pesquisa foram transcritos e demonstrados por meio de quadros, conforme os temas abordados. Assim, os tabela de número 1 a 5 referem-se aos temas abordados com os profissionais de saúde e, as tabelas de número 6 a 8, referem-se aos temas tratados com a população de usuários. Para uma melhor demonstração dos resultados, convencionou-se denominar os participantes da UBSF Rincão Bonito, de Grupo 1 e, os participantes da UBSF Vila Donária, de Grupo 2.

Em relação à composição das equipes é importante esclarecer que a ESF referente ao Grupo 1 écomposta por: 1 médico, 1 enfermeiro, 1 cirurgião dentista, 2 auxiliares de enfermagem, 1 auxiliar de dentista e 4 ACS; a ESF referente ao Grupo 2 é composta por 1 médico (que optou por não participar da pesquisa), 1 enfermeiro, 1 auxiliar de enfermagem, 1 técnico de enfermagem e 4 ACS. Desta forma, dadas as diferenças na composição das equipes, optou-se por deixar em branco os espaços destinados às respostas, de profissionais cujas categorias não integram as equipes. 
Tabela 1- Conhecimento a cerca da saúde mental da população da área adscrita.

\begin{tabular}{|c|c|c|}
\hline categorias profissionais & respostas do grupo 1 & respostas do grupo 2 \\
\hline Médico & $\begin{array}{l}\text { "Ainda não tenho total conhecimento da saúde mental } \\
\text { da população que trabalho, devido o pouco tempo de } \\
\text { atuação nesta unidade" }\end{array}$ & $\begin{array}{l}\text { Optou por não } \\
\text { participar da pesquisa }\end{array}$ \\
\hline Enfermeiros & "Sim" & “Não" \\
\hline Cirurgião Dentista & "Não" & \\
\hline Aux. De Enfermagem & $\begin{array}{l}\text { a) "Sim" } \\
\text { b) "Não" }\end{array}$ & "Não" \\
\hline Aux. De Dentista & "Não" & \\
\hline Téc. De Enferm. & & "Sim" \\
\hline ACS & $\begin{array}{l}\text { a) "Sim" } \\
\text { b) "Sim, através do uso de medicação } \\
\text { controlada" } \\
\text { c) "Sim." } \\
\text { d) "Sim." }\end{array}$ & $\begin{array}{l}\text { a) "Sim, a nossa população precisa de tratamentos } \\
\text { principalmente sobre a saúde mental, que hoje } \\
\text { em dia quase todo mundo sofre com esse } \\
\text { problema saúde mental." } \\
\text { b) "Sim; São mais de sete anos de trabalho como } \\
\text { ACS e/ou no PSF. Em todo esse tempo, venho } \\
\text { percebendo a necessidade de acompanhamento } \\
\text { mais assíduo do psicólogo." } \\
\text { c) "Sim, sei quem usa medicamento controlado, } \\
\text { quem tem problema e os usuários que são } \\
\text { encaminhados para psicólogo, médico da nossa } \\
\text { área para outra unidade." } \\
\text { d) "Sim." }\end{array}$ \\
\hline
\end{tabular}

A análise das respostas registradas na tabela 1 revela que dos componentes do Grupo 1, apenas o cirurgião dentista e o auxiliar de dentista relatam desconhecer a realidade a cerca da saúde mental da população da área. O profissional médico relata pouco conhecimento e justifica sua resposta pelo fato de estar a pouco tempo na UBSF.

Dentre os componentes do Grupo 2, apenas o profissional enfermeiro e o auxiliar de enfermagem declararam desconhecimento. Em contrapartida, o técnico de enfermagem e todos os ACS afirmam conhecer a situação da população em relação a sua saúde mental, o que pode denotar um nível maior de envolvimento destes com a comunidade residente na área.

Pode-se observar que, os profissionais de ambos os grupos, principalmente os que estão em contato mais direto com as populações das respectivas áreas, possuem algum conhecimento sobre a situação em relação a saúde mental destes. 
Tabela 2- Forma de atendimento à saúde mental da população da área adscrita.

\begin{tabular}{ll}
\hline categorias profissionais & respostas do grupo 1 \\
\hline Médico & "Em nossa equipe temos uma psicóloga que \\
& atende em nível ambulatorial os casos \\
& necessários, encaminhados pelo agente de saúde, \\
& médico e enfermeira, e por ela mesma quando \\
& em visita domiciliar. Nossa psicóloga faz palestras \\
& esclarecedoras em vários temas para a população."
\end{tabular}

respostas do grupo 2

Optou por não participar da pesquisa

\begin{tabular}{|l|l|l|l|}
\hline & $\begin{array}{l}\text { "É feito por livre demanda e por } \\
\text { encaminhamentos de agentes comunitários, } \\
\text { enfermeira e outros profissionais da } \\
\text { equipe." }\end{array}$ \\
\hline Enfermeiros & $\begin{array}{l}\text { "Por uma psicóloga, com atendimentos } \\
\text { individuais, por livre demanda e pacientes } \\
\text { encaminhados pelo médico e ACS." }\end{array}$ \\
\hline Cirurgião Dentista & $\begin{array}{l}\text { a)"Está sendo realizada em toda a população." } \\
\text { b) “Encaminhamentos espontâneos para a } \\
\text { psicóloga da unidade." }\end{array}$ \\
\hline "È atendido pelo profissional psicólogo da \\
equipe."
\end{tabular}

“No momento ainda não há atendimento de um profissional psicólogo na equipe. Os usuários que residem na área e que necessitam desse tipo de atendimento são encaminhados para o Centro de Saúde Pe. José Ferrero, entrando na fila de espera em busca de vaga, no entanto não existe uma contrareferência dos pacientes que são encaminhados."
"Encaminhado pelo médico para a unidade de saúde central."
"Somente pelo médico é encaminhado ao Posto de Saúde Central."

a) “Na nossa equipe não temos ainda um psicólogo para orientar a população."

b) "O ACS encaminha a pessoa para o médico ou diretamente para a psicóloga."

c) "Os ACS encaminham para o médico do PSF ou para a psicóloga nas outras unidades."

d) "Está sendo encaminhado para o médico, dependendo do caso, encaminha para a psicóloga em outra unidade."

Em relação a forma como está sendo feito o atendimento de saúde ment „ৈl da população, observa-se que os componentes de ambos os grupos consideram que os usuários recebem atenção em saúde mental (Tabela 2). O diferencial está no nível da atenção; enquanto a população atendida pelo Grupo 1 recebe o atendimento na própria UBSF, os atendidos pelo Grupo 2 são encaminhados à unidade de referência, entrando na fila de espera em busca de vaga.

Destaca-se que os pesquisados do Grupo 1 explicitam que o atendimento é realizado na própria unidade pelo profissional psicólogo através da livre demanda e/ou mediante encaminhamentos de ACS, médico e enfermeira, sendo importante ressaltar que, embora o profissional psicólogo não faça mais, oficialmente, parte da equipe e atenda desde o final do ano de 2001 somente dois dias da semana nesta unidade, o conteúdo da fala dos participantes da pesquisa permite inferir que, o profissional psicólogo continua sendo considerado um membro atuante da equipe, podendo indicar que o trabalho desenvolvido vem suprindo necessidades da mesma. Isto pode ser observado por meio das falas: “(...) atendido pelo profissional psicólogo da equipe.", "em nossa equipe temos uma psicóloga (...)", 
Os pesquisados do Grupo 2 referem que o atendimento em saúde mental é realizado por meio de encaminhamentos à unidade de referência. Importa ressaltar que o profissional enfermeiro do Grupo 2 expressa sentir necessidade da contra-referência, dificuldade de agendamento, uma vez que os usuários encaminhados pelo PSF enfrentam fila única de atendimento psicológico do município, por esta razão, quando do encaminhamento de pacientes para atendimento na unidade de referência, há dificuldade de vaga. Com base na resposta do profissional enfermeiro, "No momento ainda não há atendimento de um profissional psicólogo na equipe.(...)", pode-se observar alguma expectativa de vir a ter o psicólogo como membro da equipe.

Tabela 3 - Atividades desenvolvidas pela equipe em que o psicólogo é considerado importante.

\begin{tabular}{l|l} 
categorias profissionais & \multicolumn{1}{c}{$\begin{array}{c}\text { respostas do grupo } 1 \\
\text { Médico }\end{array}$} \\
& "Visitas domiciliares nos casos alvos, diagnosticados \\
pelos agentes, palestras educativas, de auto estima, \\
stress, participa junto com o médico, enfermeira e \\
dentista e demais componentes em todos os \\
programas do PSF (gestante, hipertenso, diabético, \\
controle de natalidade...)"
\end{tabular}

Enfermeiro

\section{Cirurgião Dentista}

Auxiliar de enfermagem

\section{Auxiliar de dentista}

Técnico de enfermagem

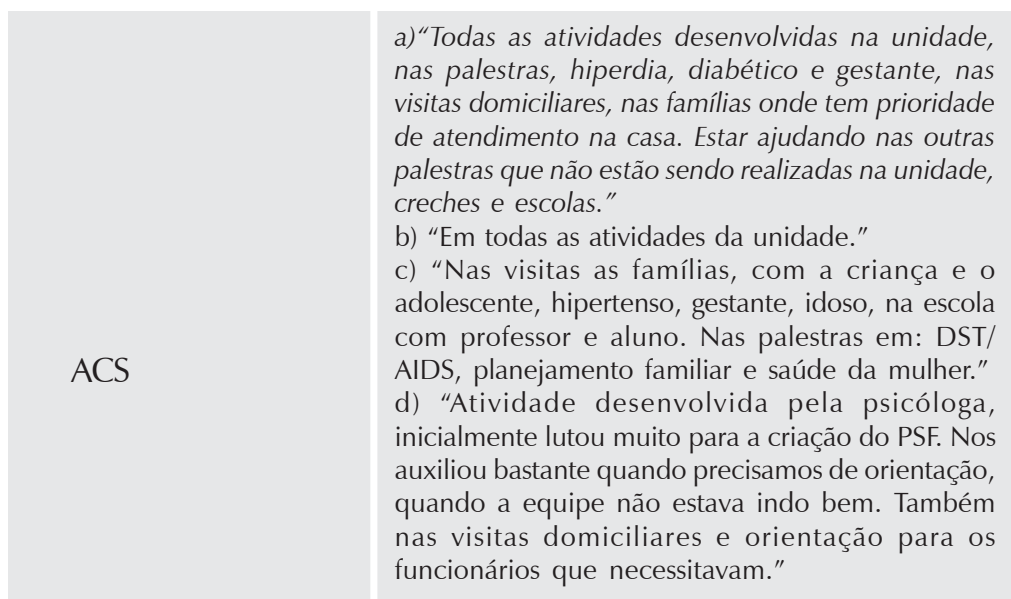

"O psicólogo seria importante em todas as atividades desenvolvidas no PSF. Principalmente nas visitas domiciliares, gestantes, adolescentes e terceira idade."

a) "Em todas as atividades desenvolvidas pela unidade."

b) "Todas as atividades desenvolvidas na unidade."

"Em todos os programas, hipertensos, diabéticos, gestantes, palestras, apoio, respaldo e segurança para enfrentamento de situações difíceis."

\section{respostas do grupo 2}

Optou por não participar da pesquisa

"Certamente em todas as atividades, desde as visitas domiciliares até as atividades em grupos como: hipertensos, gestantes, planejamento familiar... Com certeza a saúde da população, de um modo geral, melhoraria e muito."

"En todas as atividades."

a) "Dentro do PSF para as pessoas procurar ajuda."

b) "Para complementar a equipe ou seja o psicólogo para dar o apoio que a mesma precisa."

C) "Em todas mas, acho que é mais importante no hiperdia, DST/AIDS, idoso, adolescentes e quando tem que fazer trabalho em grupo, palestra de vida sexual, quando tem briga dentro da equipe."

d) "Na visita domiciliar, nos programa principalmente no hiperdia e planejamento familiar 
As respostas contidas na Tabela 3 revelam que os participantes do Grupo 1 consideraram que o psicólogo é importante em todos os programas da atenção básica; destacam que é importante a participação junto com a equipe, inclusive em visitas domiciliares e orientação aos membros da equipe que, parecem denotar um certo sentimento de segurança criado a partir da atuação do profissional psicólogo integrado à equipe “(...) nos auxiliou bastante quando precisamos de orientação, quando a equipe não estava indo bem.(...)". Observa-se ainda que, o auxiliar de dentista considera o psicólogo como profissional de apoio, no sentido de respaldar e prover segurança para o enfrentamento de situações difíceis que porventura a equipe possa vivenciar. É possível perceber que os ACS expressam um sentimento em relação ao psicólogo, como elemento de apoio e complemento em relação à equipe.

Os componentes do Grupo 2 também consideraram que o psicólogo é importante em todos os programas da atenção básica; já o auxiliar de enfermagem e o técnico de enfermagem consideram-no importante em todas as atividades desenvolvidas no âmbito do Programa de Saúde da Família.

Os ACS deste grupo citam especificamente a importância de sua participação em programas como:"(...) diabetes, hiperdia, DST/AIDS, adolescente e gestante."que, pelas próprias características da população específica a que se destinam (faixa t:tária, peculiaridades da patologia), envolvem aspectos afetivo emocionais e até conflitos psíquicos, da parte tanto do usuário quanto do trabalhador em saúde. Assim, expressa n uma necessidade de complemento para atuarem nesses aspectos."(..) para compleməntar a equipe, ou seja, para dar o apoio que a mesma precisa". O profissional, em sua esp „cificidade, é visto ainda como elemento conciliador. "Nos auxilia muito quando a equipe nćo vai bem"(...)."Quando tem que fazer trabalho em grupo, palestras, quando tem briga dentro da equipe".

Os resultados revelados nessa Tabela condizem com os expressos fior Cardoso (2002, p. 8). 
Tabela 4 - Contribuições do psicólogo para o processo de trabalho em equipe.

\begin{tabular}{|c|c|c|}
\hline categorias profissionais & respostas do grupo 1 & respostas do grupo 2 \\
\hline Médico & $\begin{array}{l}\text { "Ajuda na coesão da equipe, no relacionamento } \\
\text { entre todos os membros, nos ajudar a resolver } \\
\text { determinados problemas quando estamos } \\
\text { estressados." }\end{array}$ & Optou por não participar da pesquisa \\
\hline Enfermeiras & $\begin{array}{l}\text { "Melhoraria na qualidade da assistência prestada } \\
\text { a população." }\end{array}$ & $\begin{array}{l}\text { "Inúmeras contribuições: Relacionamento humano, } \\
\text { atendimento humanizado, abordagem de determinados } \\
\text { assuntos como: DST/AIDS, hábitos de higiene, além de } \\
\text { oferecer suporte psíquico e emocional para a equipe." }\end{array}$ \\
\hline Cirurgião Dentista & $\begin{array}{l}\text { "Como orientadora dos integrantes da equipe, } \\
\text { com palestras para o grupo e com atendimento } \\
\text { individual para quem necessitar." }\end{array}$ & \\
\hline $\begin{array}{l}\text { Auxiliar de } \\
\text { enfermagem }\end{array}$ & $\begin{array}{l}\text { a)"Pelo bem estar, e com o companheirismo." } \\
\text { b) "Apoio para a equipe e ajuda a equipe naquilo } \\
\text { que a equipe não conhece. Exemplo: } \\
\text { Comportamentos estranhos do paciente, ela } \\
\text { logo diz que tipo de paciente se trata." }\end{array}$ & "É importante por vários motivos." \\
\hline Auxiliar de dentista & $\begin{array}{l}\text { "Para que estruture melhor para } \\
\text { enfrentarmos o dia a dia." }\end{array}$ & \\
\hline Técnico de Enfermagem & & "Muitas, palestras e outros." \\
\hline ACS & $\begin{array}{l}\text { a)"Para trabalharmos todos em conjunto e } \\
\text { discutirmos como está sendo realizado nosso } \\
\text { trabalho e a psicóloga pode estar ajudando a } \\
\text { equipe." } \\
\text { b) "Apoio ao nosso trabalho que é difícil de ser } \\
\text { resolvido." } \\
\text { c) "Apoio ao nosso trabalho: Como profissional } \\
\text { apoiando nas nossas atividades difícil de ser } \\
\text { resolvida na equipe." } \\
\text { d)"A união da equipe e orientações." }\end{array}$ & $\begin{array}{l}\text { a) "Seria ótimo um psicólogo para orientar nossa } \\
\text { equipe." } \\
\text { b) “Agilizaria o trabalho do ACS, do próprio médico } \\
\text { como também das pessoas necessitadas. Devido a } \\
\text { grande demanda acaba emperrando um pouco o } \\
\text { atendimento das mesmas." } \\
\text { c) "Para a equipe ajudando a gente a resolver as brigas } \\
\text { pra ter mais harmonia no trabalho para ouvirem mais } \\
\text { os ACS para ter trabalho em grupo. Quando a gente } \\
\text { vai fazer palestras nos grupos, ajudar nos assuntos } \\
\text { que a gente tem dificuldade." } \\
\text { d) "Quase sempre nós ficamos sem saber como agir } \\
\text { em certa situação, a presença do psicólogo seria de } \\
\text { grande ajuda. A equipe sentiria mais segura para } \\
\text { enfrentar situações mais difíceis, também ficaríamos } \\
\text { bem mais tranqüilos." }\end{array}$ \\
\hline
\end{tabular}

A análise dos relatos referentes às contribuições que o profissional psicólogo pode dar para o processo de trabalho da equipe (Tabela 4), revela que o Grupo 1 refere-se à participação do profissional no sentido de promover a coesão e harmonia da equipe, ao auxílio no sentido de estruturar os membros da equipe em termos de condições emocionais para o enfrentamento da realidade quotidiana e as situações inerentes as especificidades do PSF, consideradas difíceis de enfrentar, o que pode ser observado a partir de respostas como:"Apoio ao nosso trabalho que é difícil de ser resolvido.";"Para que estruture melhor para enfrentarmos o dia a dia.";"Ajuda na coesão da equipe, no relacionamento entre todos os membros, nos ajudar a resolver determinados problemas quando estamos estressados.".

Em relação a mesma pergunta, as respostas obtidas do Grupo 2 indicam um certo desconhecimento sobre o papel do profissional psicólogo, por parte da maioria dos pesquisados, a exceção do profissional enfermeiro cuja resposta:"Inúmeras contribuições: Relacionamento humano, atendimento humanizado, abordagem de determinados assuntos como: DST/AIDS, hábitos de higiene, além de oferecer suporte psíquico e emocional para a equipe.",denota conhecimento sobre o tema. 
Tabela 5 - Contribuições que o psicólogo traria para a população.

\begin{tabular}{l} 
categorias profissionais \\
Médico \\
\hline
\end{tabular}

Enfermeiras

$$
\text { respostas do grupo } 1
$$

"Saúde mental para a população, já que a maioria das patologias tem sua vez no mental, a população também está carente de alguém que possa ouvi-los."

"Melhoria na qualidade da assistência."

\section{Cirurgião Dentista}

Auxiliar de enfermagem

Auxiliar de dentista Técnico de Enfermagem
"Para o tratamento dos problemas psico-sociais e todas as doenças psicológicas e, como orientação de grupo." respostas do grupo 2

Recusou-se a responder.
"Assim como para a equipe o psicólogo é muito importante. Na minha concepção cuidar da saúde não é apenas cuidar do bem-estar físico mas, também do bemestar emocional, mental, psicológico das pessoas. Um psicólogo completaria parte do que falta para que tenhamos um atendimento integral à saúde em nossa equipe." a) "Confiança da população de chegar na unidade e ter uma profissional na área para atende-los."

b) "Ajuda na recuperação dos familiares que também sofrem por ter na família um membro que indiretamente ou diretamente afeta a população."

"Para dar acolhimento e apoio a família."

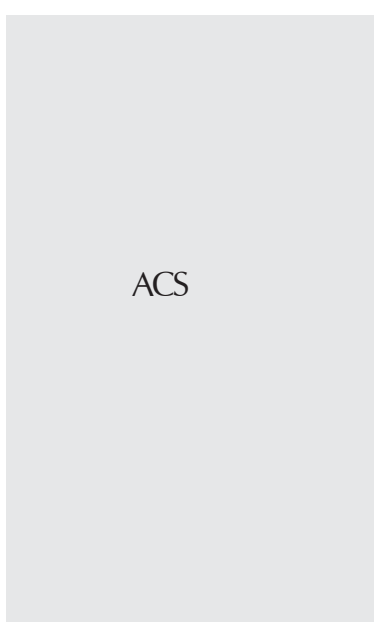

a) "Para a população ter mais respaldo dos medicamentos ou de alguns transtornos mentais ou familiares, ajudando o paciente, orientação das famílias, principalmente nas separações ou orientação dos casais e filhos."

b) "É importante pra quem tem problemas físico, emocional, social e mental."

c) "A população sente mais segura, tranqüila e ajuda no apoio as famílias que enfrentam problemas com adolescentes e familiar no modo geral."

d) "Passa segurança, orientação, respaldo, aproximação da população para a equipe. União das famílias."
"Em palestras, idosos, adolescentes e outros."

"Palestras em grupo, atendimento individual e adolescentes."

a) "Para a população ainda melhor porque as doenças aumentaram inclusive a AIDS e o Câncer, que deixaram as pessoas desorientadas."

b) "Segurança, atendimento agilizado, mais fácil locomoção da população carente, nas áreas adjacentes ao PSF. Auxiliando também o próprio ACS quanto a abordagem das pessoas, quando o mesmo adentra nos lares, após a detecção do problema pela psicóloga."

c) "Para a população ter o psicólogo mais perto, com mais facilidade de agendar, tem muita gente com problema de saúde mental na área e que precisa prevenir pra não ter que chegar a tomar remédio." d) "Principalmente o acesso ao serviço psicológico, segurança para a população, atendimento a saúde mental, fazer orientação familiar, e orientação de casal."

Em se tratando das contribuições que o psicólogo traria para a população das áreas atendidas pelas equipes de saúde da família (Tabela 5), os profissionais do Grupo 1 denotam ter conhecimento da necessidade de atenção à saúde mental da população quando respondem:"Saúde mental para a população, já que a maioria das patologias tem sua vez no mental (..)". "Para o tratamento dos problemas psico-sociais (...)". Reconhecem ainda, que o psicólogo é o profissional que possui o conhecimento para diminuir as dificuldades dos membros da equipe em lidar com questões da vida afetivo-emocional e intrapsíquica, naturais às relações humanas, em comunidade, em família e, para lidar com as tabelas de transtornos mentais. Essa atuação do profissional de saúde mental na capacitação/supervisão dos membros da equipe foi também relatada por Pereira et. al. (2003).

Os participantes do Grupo 2 destacam a importância da presença do profissional na unidade do PSF como forma de garantir e/ou facilitar o acesso da população ao atendimento em saúde mental. Destacam também a importância de sua atuação nos aspectos educativos/preventivos, por meio de palestras aos adolescentes e idosos. Observa-se ainda uma certa preocupação com o atendimento aos princípios norteadores do SUS, como a descentralização e a integralidade da assistência."(...) na minha concepção, cuidar da saúde não é apenas cuidar do bem- estar físico mas, também do bem-estar emocional, psicológico das pessoas. Um psicólogo completaria a parte que falta para que tenhamos um atendimento integral à saúde em nossa equipe". 
Tabela 6 - Conhecimento dos usuários sobre o que é um profissional psicólogo.

\begin{tabular}{|c|c|c|}
\hline no. ordem & respostas do grupo 1 & respostas do grupo 2 \\
\hline 01 & "Sim"(sexo feminino, 20 anos, babá) & "Sim"(sexo feminino, 25 anos, do lar) \\
\hline 02 & "Sim"(sexo feminino, 50 anos, funcionária pública municipal) & "Sim"(sexo feminino, 30 anos, funcionária pública) \\
\hline 03 & $\begin{array}{l}\text { "Sim"(sexo feminino, } 23 \text { anos, camareira) } \\
\text { (sexo feminino, } 32 \text { anos, balconista) }\end{array}$ & "É uma pessoa para orientar e esclarecer dúvidas". \\
\hline 04 & "Sim".(sexo feminino, 33 anos, recepcionista) & $\begin{array}{l}\text { "É uma pessoa que fala com você". (sexo feminino, } \\
37 \text { anos, saladeira) }\end{array}$ \\
\hline 05 & "Sim". (sexo feminino, 20 anos, doméstica) & "Sim". (sexo feminino, 50 anos, costureira). \\
\hline 06 & "Sim". (sexo feminino, 48 anos, recepcionista) & $\begin{array}{l}\text { "Profissional que cuida da saúde mental das pessoas". } \\
\text { (sexo masculino, } 54 \text { anos, pecuarista) }\end{array}$ \\
\hline 07 & "Não". (sexo feminino, 29 anos, doméstica) & "Não". (sexo feminino, I6 anos, estudante) \\
\hline 08 & "Profissional que atende a saúde mental". & $\begin{array}{l}\text { (sexo feminino, l8 anos, caixa de supermercado) } \\
\text { "Não". (sexo feminino, } 42 \text { anos, do lar) }\end{array}$ \\
\hline 09 & $\begin{array}{l}\text { "Sim é aquele que nos orienta". (sexo feminino, } 67 \text { anos, } \\
\text { aposentada). }\end{array}$ & \\
\hline 10 & "Para orientar a gente". (sexo feminino, 41 anos, serviços gerais) & \\
\hline
\end{tabular}

O conhecimento dos usuários sobre o que seja o profissional psicólogo conforme demonstrado na Tabela 6, não parece ser um problema para os usuários pesquisados do Grupo 1. São categóricos em responder positivamente, havendo inclusive uma resposta que o define expressamente como"profissional de saúde mental"; "aquele que orienta". Considerando a forma como a pergunta foi formulada, não favorecendo um discurso maior sobre o tema, não se percebe nenhuma insegurança nas afirmações positivas. Além disso, é importante observar que grande parte da população da área representada pelo Grupo 1, tem ou teve efetivo acesso ao trabalho do profissional psicólogo, seja em atendimentos psicoterápicos, individuais ou grupais, orientações ou palestras, de forma a permitir inferir que realmente saibam qual o papel do profissional.

Observa-se que, em contrapartida, os usuários componentes do Grupo 2 possuem, de modo geral, um conhecimento mais limitado sobre o tema, muito embora uma resposta tenha dado conta de situar o profissional como responsável pela saúde mental. Observa-se muito mais que conhecimento, o desejo de um atendimento mais humanizado:"É uma pessoa para orientar e esclarecer dúvidas"É uma pessoa que fala com você".

Tabela 7 - Utilização dos serviços do profissional psicólogo pelos usuários.

\begin{tabular}{|c|c|c|}
\hline no. ordem & respostas do grupo 1 & respostas do grupo 2 \\
\hline 01 & "Sim". (sexo feminino, 20 anos, babá). & "Sim". (sexo feminino, 25 anos, do lar) \\
\hline 02 & "Sim". (sexo feminino, 50 anos, funcionária pública municipal). & $\begin{array}{l}\text { "Sim". (sexo feminino, } 30 \text { anos, funcionária } \\
\text { pública). }\end{array}$ \\
\hline 03 & "Não". (sexo feminino, 23 anos, camareira) & "Preciso".(sexo feminino, 32 anos, balconista) \\
\hline 04 & "Sim". (sexo feminino, 33 anos, recepcionista) & "Não". (sexo feminino, 37 anos, saladeira). \\
\hline 05 & "Sim". (sexo feminino, 20 anos, doméstica) & $\begin{array}{l}\text { "Sim, no momento estou precisando". (sexo } \\
\text { feminino, } 50 \text { anos, costureira) }\end{array}$ \\
\hline 06 & "Sim". (sexo feminino, 48 anos, recepcionista) & "Sim". (sexo masculino, 54 anos, pecuarista) \\
\hline 07 & "Não". (sexo feminino, 29 anos, doméstica) & "Sim". (sexo feminino, I6 anos, estudante) \\
\hline 08 & "Sim". (sexo feminino, 18 anos, caixa de supermercado) & "Sim". (sexo feminino, 42 anos, do lar) \\
\hline 09 & $\begin{array}{l}\text { "Sim quando eu estava deprimida". } \\
\text { (sexo feminino, } 67 \text { anos, aposentada) }\end{array}$ & \\
\hline 10 & $\begin{array}{l}\text { "Sim para me orientar". } \\
\text { (sexo feminino, } 41 \text { anos, serviços gerais) }\end{array}$ & \\
\hline
\end{tabular}


Tabela 8 - Necessidade do profissional psicólogo na equipe saúde da família, sob o ponto de vista do usuário.

\begin{tabular}{|c|c|c|}
\hline no. ordem & respostas do grupo 1 & respostas do grupo 2 \\
\hline 01 & $\begin{array}{l}\text { "Sim, por estar perto de casa e sou atendida no centro de } \\
\text { saúde e na minha casa". (sexo feminino, } 20 \text { anos babá) }\end{array}$ & $\begin{array}{l}\text { "Sim, para ajudar as pessoas". (sexo feminino, } 25 \\
\text { anos, do lar) }\end{array}$ \\
\hline 02 & $\begin{array}{l}\text { "Sim por ter acesso ao serviço psicológico mais próximo a } \\
\text { casa". (sexo feminino, } 50 \text { anos, funcionária pública } \\
\text { municipal) }\end{array}$ & $\begin{array}{l}\text { "Sim. Por vários motivos porque muita gente precisa, assim } \\
\text { como eu já precisei". (sexo feminino, } 30 \text { anos, funcionária } \\
\text { pública) }\end{array}$ \\
\hline 03 & $\begin{array}{l}\text { "Sim, pois as vezes as pessoas vem a precisar e não ter } \\
\text { condições de pagar". (sexo feminino, } 23 \text { anos, camareira) }\end{array}$ & $\begin{array}{l}\text { "Sim, por estar mais próximo das casas aonde precisa } \\
\text { de ajuda". (sexo feminino, } 32 \text { anos, balconista) }\end{array}$ \\
\hline 04 & $\begin{array}{l}\text { "Sim, para que a população tenha acesso mais rápido e } \\
\text { atendimento nas suas residências. Precisamos dar } \\
\text { continuidade da psicóloga na unidade". (sexo feminino, } 33 \\
\text { anos, recepcionista) }\end{array}$ & $\begin{array}{l}\text { "Para conversar com as pessoas os problemas da } \\
\text { família". (sexo feminino, } 37 \text { anos, saladeira). }\end{array}$ \\
\hline 05 & $\begin{array}{l}\text { "Sim, por que as vezes a gente precisa muito de uma } \\
\text { orientação e a psicóloga está mais perto da minha casa". } \\
\text { (sexo feminino, } 20 \text { anos, doméstica) }\end{array}$ & $\begin{array}{l}\text { "Sim. Porque precisa mesmo, faz muita falta, se } \\
\text { precisamos temos que pagar. É muito importante". } \\
\text { (sexo feminino, } 50 \text { anos, costureira) }\end{array}$ \\
\hline 06 & $\begin{array}{l}\text { "Sim, tem muita gente que precisa e esta perto de nossa } \\
\text { casa". (sexo feminino, } 48 \text { anos, recepcionista) }\end{array}$ & $\begin{array}{l}\text { "Sim, porque na unidade saúde da família facilita o } \\
\text { acesso às pessoas desta comunidade". (sexo } \\
\text { masculino, } 54 \text { anos, pecuarista) }\end{array}$ \\
\hline 07 & $\begin{array}{l}\text { "Porque tem pessoas que precisa, porque a psicóloga está } \\
\text { perto de nós". (sexo feminino, } 29 \text { anos, doméstica) }\end{array}$ & $\begin{array}{l}\text { "Sim, porque tem gente que não é certo da idéia". } \\
\text { (sexo feminino, } 16 \text { anos, estudante) }\end{array}$ \\
\hline 08 & $\begin{array}{l}\text { "Sim. Melhor comodidade, ter mais acesso ao trabalho do } \\
\text { profissional, mais rápido..". (sexo feminino, } 18 \text { anos, caixa de } \\
\text { supermercado) }\end{array}$ & $\begin{array}{l}\text { "Sim. É muito necessário para essa comunidade". } \\
\text { (sexo feminino, } 42 \text { anos, do lar) }\end{array}$ \\
\hline 09 & $\begin{array}{l}\text { "Sim, pra gente ter apoio quando estiver desorientado". (sexo } \\
\text { feminino, } 67 \text { anos, aposentada) }\end{array}$ & \\
\hline 10 & $\begin{array}{l}\text { "Sim para nos apoiar nas horas difíceis". (sexo feminino, } 41 \\
\text { anos, serviços gerais) }\end{array}$ & \\
\hline
\end{tabular}

Conforme demonstrado na Tabela 8, ambos os grupos são unânimes em manifestar que o psicólogo é um profissional necessário na composição da equipe de PSF, por possibilitar que a atenção à saúde mental esteja o mais próximo possível daqueles que necessitam e sofrem quando não tem acesso a esses serviços.

Atendimento rápido e próximo de suas residências são necessidades manifestas pelos que vêem o psicólogo como"o profissional que conversa, orienta as pessoas e as famílias".

Os componentes do Grupo 1 justificam sua assertiva mediante principalmente, o argumento de que proporciona o acesso ao serviço psicológico mais próximo de suas residências.

Entre os componentes do Grupo 2, destaca-se que embora as respostas sejam em totalidade positivas, manifestando o desejo de ter o profissional na ESF, as justificativas diferem entre si, surge o argumento de que haveria uma maior facilidade de acesso para a população da área para uns e, enquanto outros fazem referência a necessidade de atendimento psicológico e/ou orientação para justificar sua resposta positiva.

\section{Conclusão}

A pesquisa revela que na área estudada existe uma real preocupação por parte tanto de profissionais quanto de usuários, com relação a saúde mental, tanto sob uma perspectiva individual ("Para que estruture melhor para enfrentarmos o dia a dia.") quanto coletiva ("Sim, a nossa população precisa de tratamentos principalmente sobre a saúde mental); e que na realidade pesquisada o profissional psicólogo é fortemente identificado com o papel de facilitador das práticas geradoras de saúde mental, de melhoria de qualidade de vida, sendo percebido como alguém a quem se pode recorrer na busca de acolhimento, em situações consideradas difíceis. Além disso, para o usuário sua presença na equipe satisfaz o desejo de acesso e humanização dos serviços. 
Pode-se concluir que, a experiência de ter cotidianamente o profissional psicólogo inserido na equipe, foi considerada positiva por profissionais e usuários, que manifestam claramente sua opinião sobre a necessidade do psicólogo, do atendimento em saúde mental, embora nem todos destaquem que este deve estar incluído na equipe básica, o que ocorreu mais nas respostas obtidas junto aos profissionais que, inclusive não deixaram de considerar o profissional como um membro integrado a equipe.

Os papéis atribuídos ao profissional psicólogo neste contexto específico foram diversos. As referências ocorrem definindo-o claramente como profissional de saúde mental, ocorrem no sentido de destacar sua importância para a melhoria da qualidade das relações internas da equipe e desta com os usuários, na promoção do atendimento integral, e na humanização do atendimento, apontando para a percepção de que a participação do psicólogo no PSF é benéfica e importante.

\section{Sugestões/recomentações}

Considerando que o município não dispõe de outros profissionais na área de saúde mental (médico psiquiatra e neurologista), que possam prestar assistência à saúde dos portadores de transtornos mentais e comportamentais, a atuação do psicólogo junto às equipes possibilitaria, por meio de atuação interdisciplinar, o suporte clínico aos demais profissionais, especialmente ao médico generalista. Nesse sentido, é que se recomenda aos municípios, que disponham de equipe ampliada, contemplando a participação do profissional psicólogo. 


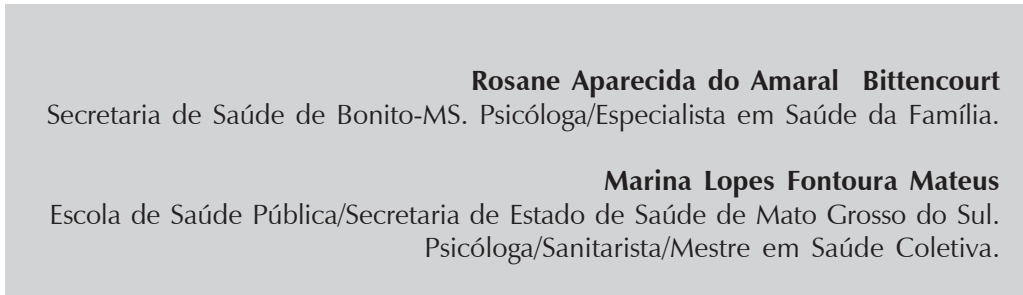

Recebido 27/01/03 Reformulado 13/02/06 Aprovado 14/03/06

BRASIL, LEI No. 10.216, de 06 de abril de 2001.

CARDOSO, C.L A inserção do psicólogo no Programa Saúde da Família: Revista Psicologia, Ciência e Profissão. Número 1, Ano 22. CFP. Brasília: 2002. p. 2 a 9.

MACHADO, M. H. (Coord.) Perfil dos médicos e enfermeiros do Programa Saúde da Famíla noBrasil. Rio de Janeiro: Ministério da Saúde/ FIOCRUZ, 2000.

MINISTÉRIO DA SAÚDE. Departamento de Atenção Básica. Guia prático do programa de Saúde da Família. Braślia: 2001a.

."Proposta Preliminar - Plano de Inclusão das Ações de Saúde Mental na Atenção Básica", Brasilia, março de 2001b. Disponível em: http://www.saudemental.med.br/PSF.htm . Acessado em: 13 de outubro de 2003
PEREIRA A. et. al. Programa de Saúde da Família e Saúde Mental: A Experiência de Sobral- CE. Disponível em: http:// www.sobral.ce.gov/saudedafamilia/Publicaçoes/Smental/ saude_familia.htm. Acessado em 07 de outubro de 2003.

PEREIRA FILHA et. al. Relato de experiência, La Insignia. Brasil. Disponível em: http://www.lainsignis.org/2003/septiembre/ soc_008.htm. Acessado em 13 de outubro de 2003.

PINTO, G. S. C. J. A Abordagem aos transtornos mentais graves na Atenção Básica. Trabalho apresentado na I Oficina de Capacitação de Supervisores em Saúde Mental para o Programa de Saúde da Família. Pólo de Capacitação em Saúde da Família do Estado do Rio de Janeiro. Itaipava - RJ, 2002. Disponível em: http:// www.saudemental.med.br/taip.html/htm. Acessado em: 20 de outubro de 2003 